\title{
PENGARUH CROSS-BRACE PADA BAGIAN UJUNG STRUKTUR RANGKA BATANG (TRUSS) GERBANG TOL SEMARANG-BATANG TERHADAP PERIODE NATURAL, LENDUTAN, DAN BERAT SENDIRI STRUKTUR
}

\author{
Kusdiman Joko Priyanto \\ Program Studi Teknik Sipil, Fakultas Teknik, Universitas Tunas Pembangunan, Surakarta \\ kusdiman.joko@lecture.utp.ac.id \\ Erik Wahyu Pradana \\ Program Studi Teknik Sipil, Fakultas Teknik, Universitas Sebelas Maret, Surakarta \\ erikwpradana@staff.uns.ac.id
}

\begin{abstract}
Abstrak
Berdasarkan data Badan Pengatur Jalan Tol (BPJT), hingga tahun 2020 terdapat terdapat 472 gerbang tol dalam 57 ruas jalan tol (dengan panjang total $1961.91 \mathrm{~km}$ ) yang telah terbangun dan beroperasi di Indonesia. Secara umum sistem struktur yang digunakan pada gerbang tol berupa portal baja dengan rangka atap menggunakan sistem rangka batang (truss). Standar desain menetapkan bahwa struktur gerbang tol harus memenuhi kondisi batas kekuatan (strength) dan layan (serviceability). Pada kondisi batas kekuatan (strength), struktur harus didesain mampu mendukung kombinasi beban rencana. Sedangkan pada kondisi batas layan (serviceability), struktur harus didesain agar lendutannya lebih kecil dibanding lendutan izin. Dalam penelitian ini akan dikaji pengaruh penggunaan cross-brace pada bagian ujung struktur rangka batang terhadap lendutan struktur, periode natural struktur, dan berat sendiri struktur. Penelitian ini dilakukan dengan mengambil studi kasus pada struktur gerbang tol pada ruas jalan tol Semarang-Batang dengan panjang bentang $31 \mathrm{~m}$. Berdasarkan model numerik yang dikembangkan, disimpulkan bahwa penggunaan cross-brace dapat menurunkan periode natural dan lendutan di tengah bentang struktur berturut-turut sebesar 0,002 s/d 0,091 detik dan $0,9 \mathrm{~s} / \mathrm{d} 1,5 \mathrm{~mm}$. Namun demikian, penggunaan penggunaan cross-brace meningkatkan berat sendiri struktur sebesar 0,247 s/d 3,755 ton. Lebih lanjut, profil HB 100.100.6.8 merupakan profil baja yang paling efektif digunakan sebagai cross-brace pada studi kasus ini, dibuktikan dengan nilai rasio penurunan lendutan dan peningkatan berat sendiri struktur yang paling besar di antara profil lainnya.
\end{abstract}

Kata kunci: rangka batang, cross-brace, lendutan

\begin{abstract}
Based on the Badan Pengatur Jalan Tol (BPJT) data, until 2020 there are 472 toll gates in 57 toll roads (with a total length of $1961.91 \mathrm{~km}$ ) that have been built and operated in Indonesia. In general, the steel frame structural system used for the toll gates with a truss system used for the roof structure. Design standards mentioned that the toll gate structure should comply the strength and service limit states. In the strength limit states, the structure must be design to be able to resist the design load combination. While in the service limit states, the structure must be designed so that the deflection is smaller than allowable deflection. This research will study the effect of cross-brace at the end of the truss structure on the deflection, structural natural period, and self weight of the structure. This research was conducted by taking a case study on the toll gate structure on the Semarang-Batang toll road with a length of $31 \mathrm{~m}$. Based on the developed numerical model, it was concluded that the use of a cross-brace can reduce the natural period and deflection in the middle of the structure span by 0.002 to 0.091 seconds and 0.9 to 1.5 $\mathrm{mm}$, respectively. However, the use of cross-brace increases the structural self weight by 0.247 to 3.755 tons. Furthermore, HB 100.100.6.8 is the most effective steel profile to be
\end{abstract}


used as a cross-brace in this case study, as evidenced by the value of the reduction in deflection and weight gain ratio of the structure is the largest among other profiles.

Keywords: truss, cross-brace, deflection

\section{PENDAHULUAN}

Pembangunan infrastruktur jalan tol merupakan salah satu proyek strategis nasional. Secara umum menurut Badan Pengatur Jalan Tol (BPJT) pembangunan infrastruktur jalan tol bertujuan untuk: (1) memperlancar lalu lintas pada daerah yang telah berkembang, (2) meningkatkan pelayanan distribusi barang dan jasa guna menunjang pertumbuhan ekonomi, (3) meningkatkan pemerataan hasil pembangunan dan keadilan, dan (4) meringankan beban dana pemerintah melalui partisipasi pengguna jalan.

Infrastruktur jalan tol untuk pertama kalinya beroperasi di Indonesia pada tahun 1978 melalui jalan tol Jagorawi. Jalan tol ini memiliki panjang total $59 \mathrm{~km}$ (termasuk jalan akses) dan menghubungkan Jakarta, Bogor, dan Ciawi. Pembangunan infrastruktur jalan tol di Indonesia terus berlanjut hingga pada periode 1995-1997 pemerintah melakukan upaya percepatan pembangunan jalan tol. Pada rentang tahun tersebut direncanakan akan dibangun infrastruktur jalan tol sepanjang 762 km. Namun demikian upaya ini harus tertunda akibat krisis moneter. Akibatnya, ruas jalan tol di Indonesia hanya bertambah $13,30 \mathrm{~km}$ pada rentang tahun 1997-2001. Pada tahun 2005 pemerintah membentuk Badan Pengatur Jalan Tol (BPJT) yang berperan sebagai regulator jalan tol di Indonesia dan menjadi salah satu upaya pemerintah dalam mempercepat pembangunan jalan tol yang sempat tertunda akibat krisis moneter. Hal ini terbukti telah membuahkan hasil dimana berdasarkan data Badan Pengatur Jalan Tol (BPJT) hingga tahun 2020 terdapat 57 ruas jalan tol (dengan panjang total $1961.91 \mathrm{~km}$ ) yang telah terbangun dan beroperasi di Indonesia. Menurut data GIS BPJT hingga tahun 2020 terdapat 472 gerbang tol dalam ruas jalan tol tersebut (lihat Gambar 1).

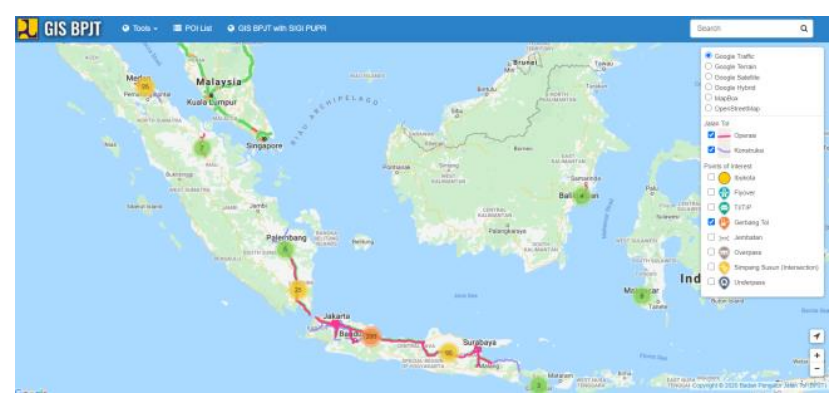

Gambar 1. Jumlah gerbang tol pada ruas jalan tol yang telah terbangun dan beroperasi di Indonesia (sumber: GIS BPJT, 2020)

Secara umum sistem struktur yang digunakan pada gerbang tol berupa portal baja dengan rangka atap menggunakan sistem rangka batang (truss). Mengingat pembangunan infrastruktur jalan tol yang masih terus berjalan dan berkembang maka kebutuhan gerbang tol juga akan terus meningkat. Untuk itu struktur gerbang tol harus didesain dengan baik agar diperoleh hasil desain yang memenuhi standar desain yang berlaku serta ekonomis. Pada standar desain, ditetapkan bahwa struktur gerbang tol harus memenuhi kondisi batas kekuatan (strength) dan layan (serviceability). Pada kondisi batas kekuatan (strength), setiap elemen struktur baja harus didesain untuk mampu mendukung beban-beban rencana. 
Sedangkan pada kondisi batas layan konfigurasi struktur rangka batang baja sebagai (serviceability), struktur harus didesain agar efisiensi struktur. Penelitian tersebut dikerjakan lendutannya lebih kecil dibanding lendutan izin. Jika kondisi batas layan (serviceability) belum terpenuhi, ada beberapa metode yang dapat dilakukan untuk mengurangi lendutan struktur seperti memperbesar dimensi profil baja yang digunakan, menambahkan pengaku (bracing) untuk meningkatkan kekakuan struktur, mengubah geometri struktur, dll.

Dalam penelitian ini akan dikaji pengaruh penggunaan cross-brace pada bagian ujung struktur rangka batang dalam mengurangi lendutan struktur. Selain itu juga akan diteliti pengaruh penggunaan cross-brace pada bagian ujung struktur rangka batang terhadap lendutan struktur, periode natural struktur, dan berat sendiri struktur. Penelitian ini dilakukan dengan mengambil studi kasus pada struktur gerbang tol pada ruas jalan tol Semarang-Batang berupa struktur portal baja dan rangka batang (truss) dengan bentang $31 \mathrm{~m}$. Terdapat 8 variasi profil baja tipe HB yang digunakan sebagai crossbrace pada penelitian ini(lihat Tabel 1). Selanjutnya dikembangkan dua model numerik yaitu struktur gerbang tol tanpa cross-brace dan dengan cross-brace untuk mengetahui periode natural struktur, lendutan struktur di tengah bentang, dan berat sendiri struktur pada kedua model numerik tersebut.

Beberapa penelitian mengenai optimasi struktur rangka batang (truss) telah dilakukan oleh beberapa peneliti terdahulu. Chouhan et al., (2017) melakukan penelitian mengenai optimasi 


\section{SISTEM STRUKTUR RANGKA III. METODE PENELITIAN}

\section{BATANG (TRUSS)}

Sistem struktur yang digunakan pada gerbang tol Semarang-Batang berupa struktur portal baja satu lantai. Sistem struktur tersebut terdiri dari kolom yang menggunakan profil baja tipe $\mathrm{KC}$ (King Cross) dan rangka atap berupa rangka batang (truss) yang menggunakan profil baja tipe HB dan UNP. Sistem struktur gerbang tol eksisting dalam perspektif 3D dan 2D berturutturut disajikan pada Gambar 2 dan 3.

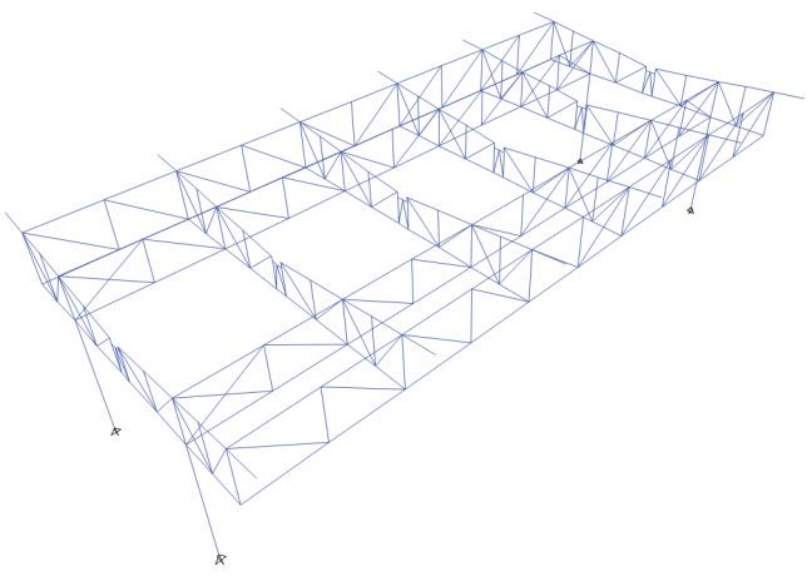

Gambar 2. Desain struktur gerbang tol eksisting dalam perspektif $3 \mathrm{D}$

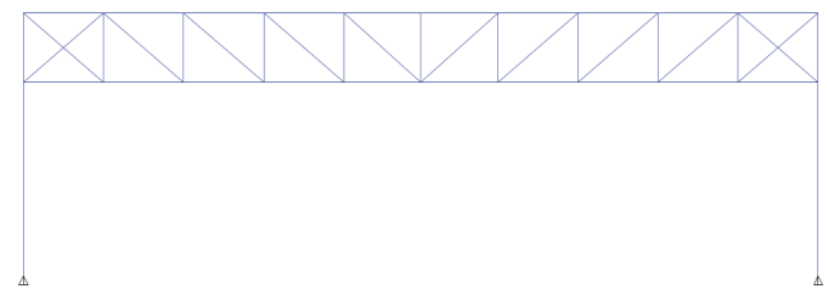

Gambar 3. Desain struktur gerbang tol eksisting dalam perspektif $2 \mathrm{D}$

Material baja yang digunakan pada sistem struktur gerbang tol Semarang-Batang memiliki tegangan leleh, $\mathrm{f}_{\mathrm{y}}=240 \mathrm{MPa}$ dengan tegangan ultimit, $f_{u}=370 \mathrm{MPa}$. Beban rencana yang dipertimbangkan dalam desain meliputi berat sendiri struktur, beban mati tambahan, beban hidup, beban angin, dan beban gempa.

\section{A. Pemodelan Struktur}

Pada penelitian ini dikembangkan dua model numerik yaitu struktur gerbang tol tanpa crossbrace dan dengan cross-brace. Model struktur tersebut dalam perspektif 2D berturut-turut disajikan pada Gambar 4 dan 5.

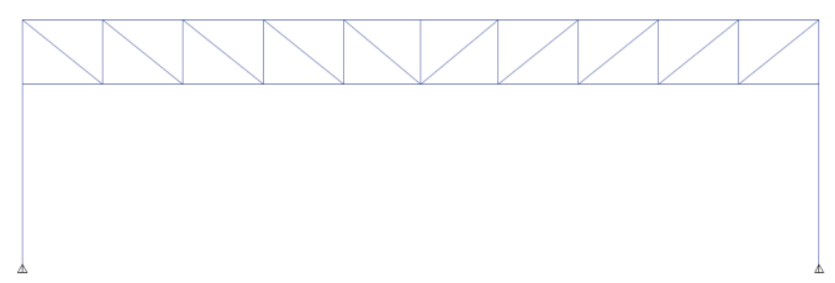

Gambar 4. Model struktur tanpa cross-brace

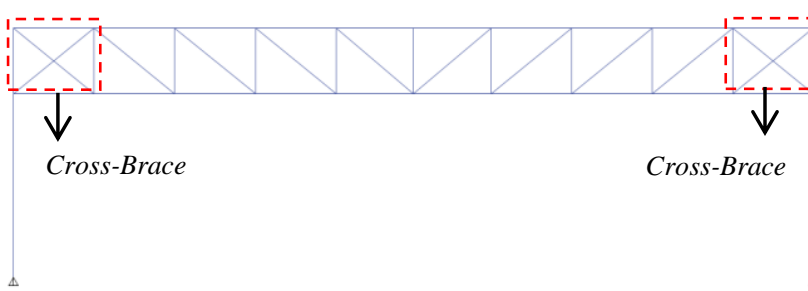

Gambar 5. Model struktur dengan cross-brace

\section{B. Variasi Profil Baja Pada Cross-Brace}

Pada model struktur gerbang tol dengan crossbrace digunakan 8 variasi profil baja tipe $\mathrm{HB}$ (lihat Tabel 1). dikembangkan dua model numerik yaitu struktur gerbang tol tanpa crossbrace dan dengan cross-brace untuk mengetahui periode natural struktur, lendutan struktur di tengah bentang, dan berat sendiri struktur pada kedua model numerik tersebut.

Tabel 1. Variasi profil baja tipe HB yang digunakan sebagai cross-brace

\begin{tabular}{cc}
\hline \hline $\begin{array}{c}\text { Tipe } \\
\text { Stuktur }\end{array}$ & Jenis Profil Cross-Brace \\
\hline 1 & Tanpa Cross-Brace \\
2 & HB 100.100.6.8 \\
3 & HB 125.125.6,5.9 \\
4 & HB 150.150.7.10 \\
5 & HB 175.175.7.5.11 \\
6 & HB 200.200.8.12 \\
7 & HB 250.250.9.14 \\
8 & HB 300.300.10.15 \\
9 & HB 350.350.12.19 \\
\hline \hline
\end{tabular}




\section{HASIL DAN PEMBAHASAN}

\section{A. Periode Natural Struktur}

Pengaruh penggunaan cross-brace pada ujung struktur rangka batang (truss) terhadap periode natural struktur disajikan pada Gambar 6. Pada Gambar 6 terlihat bahwa penggunaan crossbrace dapat menurunkan periode natural struktur. Artinya, penggunaan cross-brace dapat meningkatkan kekakuan global struktur. Sebagai contoh, penggunaan cross-brace HB 100.100.6.8 dapat menurunkan periode struktur 0,002 detik.

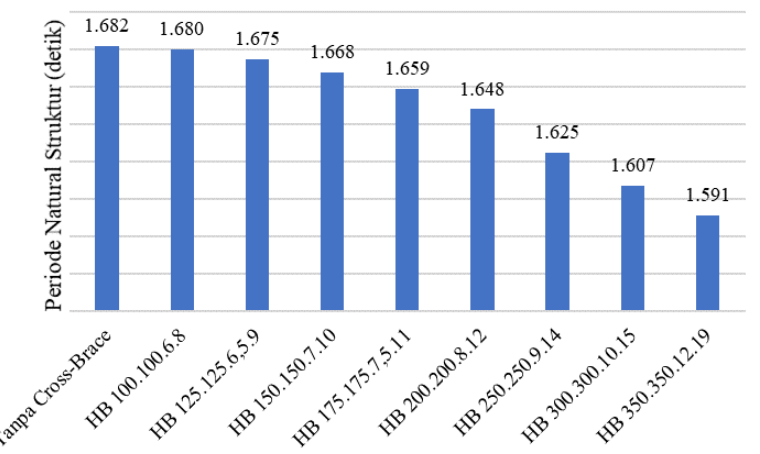

Gambar 6. Pengaruh cross-brace terhadap periode natural struktur

\section{B. Lendutan di Tengah Bentang}

Pengaruh penggunaan cross-brace pada ujung struktur rangka batang (truss) terhadap lendutan di tengah bentang struktur disajikan pada Gambar 7.

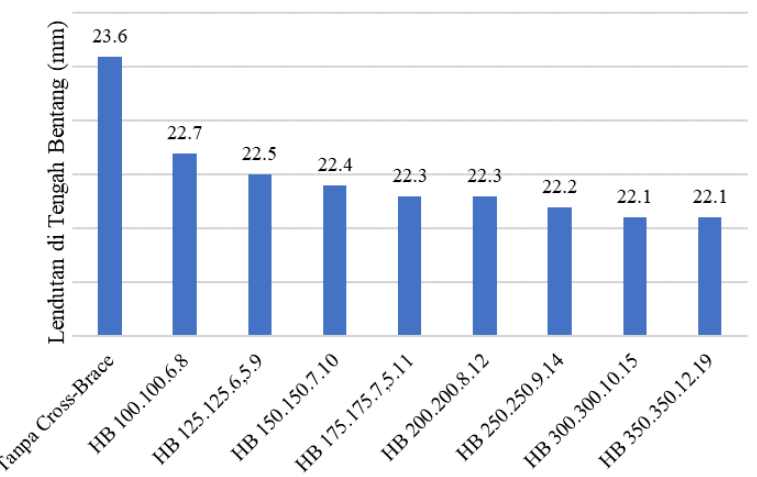

Gambar 7. Pengaruh cross-brace terhadap lendutan di tengah bentang struktur
Pada Gambar 7 terlihat bahwa penggunaan cross-brace dapat menurunkan lendutan di tengah bentang struktur. Hal ini disebabkan oleh kekakuan struktur yang meningkat akibat penggunaan cross-brace sehingga dapat mengurangi lendutan struktur di tengah bentang. Sebagai contoh, penggunaan cross-brace $\mathrm{HB}$ 100.100.6.8 dapat menurunkan lendutan di tengah bentang $0,9 \mathrm{~mm}$.

Lendutan izin pada struktur rangka batang (truss) dengan bentang $31 \mathrm{~m}$ ditetapkan sebesar L/480 yaitu 27,083 mm. Dengan demikian, lendutan di tengah bentang struktur rangka batang (truss) dengan atau tanpa cross-brace, semuanya bernilai kurang dari lendutan izin sehingga memenuhi kondisi batas layan.

\section{Berat Sendiri Struktur}

Pengaruh penggunaan cross-brace pada ujung struktur rangka batang (truss) terhadap berat sendiri struktur disajikan pada Gambar 8.

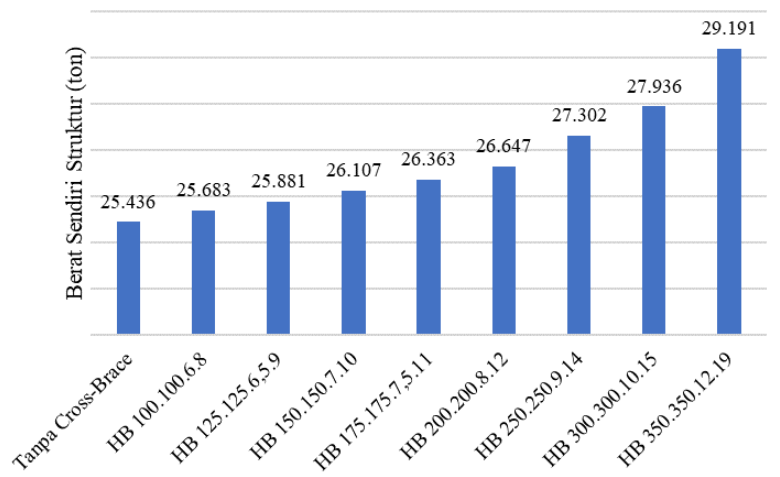

Gambar 8. Pengaruh cross-brace terhadap berat sendiri struktur

Pada Gambar 8 terlihat bahwa penggunaan cross-brace meningkatkan berat sendiri struktur. Hal ini dapat dipahami karena penggunaan cross-brace melibatkan penambahan elemen 
baru pada struktur rangka batang (truss) sehingga akan meningkatkan berat sendiri struktur. Sebagai contoh, penggunaan crossbrace HB 100.100.6.8 dapat meningkatkan berat sendiri struktur 0,247 ton.

\section{Rasio Lendutan-Berat Sendiri Struktur}

Untuk mengetahui profil baja yang paling efektif digunakan sebagai cross-brace maka digunakan parameter rasio penurunan lendutan di tengah bentang struktur dan peningkatan berat sendiri struktur. Semakin besar nilai rasio tersebut artinya penggunaan profil baja yang dimaksud pada cross-brace dapat menurunkan lendutan di tengah bentang struktur namun peningkatan berat strukturnya bernilai kecil.

Pada Gambar 9 terlihat bahwa penggunaan profil HB 100.100.6.8 pada cross-brace memiliki rasio penurunan lendutan di tengah bentang struktur dan peningkatan berat sendiri struktur paling besar dibandingkan dengan profil lainnya. Hal ini menunjukkan bahwa profil HB 100.100.6.8 merupakan profil baja yang paling efektif digunakan sebagai cross-brace pada studi kasus ini.

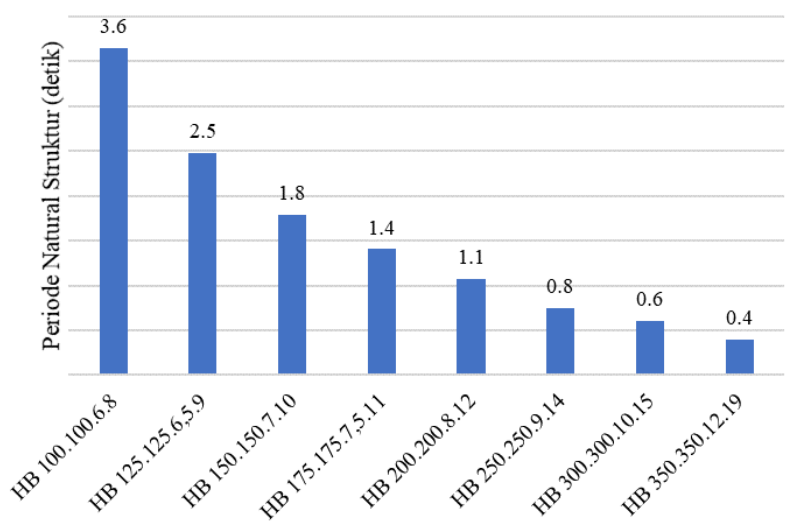

Gambar 9. Pengaruh cross-brace terhadap rasio penurunan lendutan di tengah bentang struktur dan peningkatan berat sendiri struktur

\section{KESIMPULAN}

Berdasarkan analisis yang telah dilakukan dalam penelitian ini, dapat diambil kesimpulan sebagai berikut:

1. Penggunaan cross-brace mengakibatkan penurunan periode natural struktur sebesar 0,002 s/d 0,091 detik

2. Penggunaan cross-brace mengakibatkan penurunan lendutan di tengah bentang sebesar $0,9 \mathrm{~s} / \mathrm{d} 1,5 \mathrm{~mm}$

3. Penggunaan cross-brace mengakibatkan peningkatan berat sendiri struktur sebesar $0,247 \mathrm{~s} / \mathrm{d} 3,755$ ton

4. Profil HB 100.100.6.8 merupakan profil baja yang paling efektif digunakan sebagai crossbrace pada studi kasus ini, dibuktikan dengan nilai rasio penurunan lendutan dan peningkatan berat sendiri struktur yang paling besar di antara profil lainnya.

\section{DAFTAR PUSTAKA}

Arifi, E., Hidayat, M. T., \& Grahadika, H. E. (2016). Pengaruh Konfigurasi Rangka dan Optimasi Profil Terhadap Kinerja Pada Struktur Jembatan Rangka Baja. Rekayasa Sipil, 10(3), 187-193. https://doi.org/10.21776/ub.rekayasasipil.20 16.010.02.03

Cazacu, R., \& Grama, L. (2014). Steel Truss Optimization Using Genetic Algorithms and FEA. Procedia Technology, 12, 339-346. https://doi.org/10.1016/j.protcy.2013.12.496

Chouhan, S., Sharma, R., \& Gupta, A. (2017). Optimization of steel truss configuration for structural efficiency using STAAD. Pro and ETABS. International Journal of Advance Research in Science and Engineering, 6(09), $1-11$.

Krajewski, M., \& Iwicki, P. (2015). Analysis of brace stiffness influence on stability of the 
truss. International Journal of Applied Mechanics and Engineering, 20(1), 97-108.

https://doi.org/10.1515/ijame-2015-0007 